\title{
БЕЛОРУССКО-КИТАЙСКОЕ СОТРУДНИЧЕСТВО \\ В СФЕРЕ ТУРИЗМА: СОСТОЯНИЕ И ПЕРСПЕКТИВЫ РАЗВИТИЯ
}

\author{
Л. М. ГАЙДУКЕВИЧ \\ Белорусский государственный университет, \\ Минск, Республика Беларусь
}

\begin{abstract}
Аннотация. В статье рассматривается проблематика формирования единой туристической политики в рамках Евразийского экономического союза в отношении КНР. На примере сотрудничества Республики Беларусь и Китайской народной республики раскрыта специфика и используемые инструменты взаимодействия двух стран начиная с 2014 по 2020 гг. Особое значение оба государства уделяют сотрудничеству в гуманитарной области, где туризм выступает эффективным инструментом современной коммуникационной политики.

Автор обращает внимание на опыт Китайской Народной Республики (KHP), которая первой выдержала удар коронавируса COVID-19 и в настоящее время показывает образец достаточно эффективного восстановления, в том числе и туристического бизнеса. Проанализированы основные тенденции современного международного туристического рынка, показана поэтапная активизация международного сотрудничества Беларуси и Китая в туристической сфере, раскрыта специфика безвизовой политики Беларуси с КНР, описаны особенности двухсторонних отношений в организации туристического обмена с Китайской Народной Республикой, определены главные направления, проблемы и перспективы развития туризма. Подчеркивая близость Беларуси и России, автор говорит о необходимости совместных экскурсионных программ для китайских туристов и использовании потенциала Союзного государства России и Беларуси, который в настоящее время недостаточно востребован. Особое внимание уделяется перспективному направлению, которое может привлечь китайских путешественников - медицинскому туризму.

Также автор подробно описал трудности, не позволяющие нарастить въездной поток в Беларусь, с которыми сталкиваются белорусские туристические фирмы при работе с туристами из КНР, и дает рекомендации для решения этих проблем.
\end{abstract}

Ключевые слова: туризм; туристические услуги; белорусско-китайское сотрудничество; безвизовая политика; пандемия; COVID-19.

Образец цитирования: Гайдукевич Л.М. Белорусско-китайское сотрудничество в сфере туризма: состояние и перспективы развития // Актуальные проблемы международных отношений и глобального развития: сб. науч. статей. Минск, 2021. Вып. 9. С. 27-36. https://doi.org/10.33581/2311-9470-2021-9-27-36

Введение. Последствия коронавируса COVID-19 тяжело сказались на социально-экономическом развитии многих государств. 
Наиболее уязвимым сектором мировой экономики стал международный туризм, совокупные убытки которого за прошедший период превысили 1,2 трлн долл. США. Но это экономические последствия. Более сложную ситуацию пандемия создала в системе межгосударственных и межличностных отношений. Длительный локдаун в большинстве европейских государств вызвал закрытие национальных границ в рамках Шенгенских договорённостей (закрытие границ Чехией, Австрией, Швецией, Голландией, Венгрией и др.).

Однако вся история развития международного туризма свидетельствует о наибольшей восприимчивости именно туризма к восстановлению после кризисных явлений. В этих условиях заслуживает внимания опыт Китайской народной республики (КНР), которая первой выдержала удар пандемии и в настоящее время показывает образец достаточно эффективного восстановления, в том числе и туристического бизнеса. По данным Китайской туристической академии, индустрия туризма Китая в 2019 г. продолжала усиленно развиваться. Общие доходы от туризма составили 955,3 мдрд долл. США, что на $11 \%$ больше, чем в 2018 г. Данный прирост был осуществлен за счет развития внутреннего туризма - более 6 млрд туристических поездок было совершено по стране, причем 4,47 млрд внутренних поездок совершили жители китайских городов и 1,54 млрд - жители села [1].

Методы исследования. При написании статьи автор опирался на принцип историзма, использовал общенаучные (анализ, синтез, сравнение, обобщение, дедукция) и специальные исторические методы (историко-генетический, историко-сравнительный структурный подход, системный подход), применил аналитические методики (метод описательного анализа).

Объект исследования - международный туризм в структуре региональных интеграционных объединений. Предмет исследования белорусско-китайское сотрудничество в сфере международного туризма. Цель настоящей статьи - изучение особенностей белорусскокитайского сотрудничества в сфере туризма на современном этапе, а также состояние и перспективы его развития.

Обзор литературы по теме. Белорусско-китайское сотрудничество стало особой областью исследований белорусских ученых (В. Мацель, Л. Криштапович, К. Рудый, В. Мясников, Э. Чебанова) в новейший период развития $[4,5,6,7,8]$. Однако вопросы белорусскокитайского сотрудничества в сфере туризма крайне недостаточно исследованы в республике. Как правило, этой проблематике посвящены 
в основном отдельные публикации в СМИ, а научные публикации единичны (Гэ Инь, Л.М. Гайдукевич, Е.В. Пильгун) [2, 3].

Результаты исследования. Китайское руководство придаёт большое значение развитию туризма в рамках реализации проекта «Один пояс, один путь». Как же наша республика использует возможности данного проекта для развития белорусско-китайского туристического обмена?

Необходимо отметить, что сотрудничество двух стран в сфере туризма началось ещё в 2014 г., когда был дан старт работе Межправительственного комитета по сотрудничеству высшего уровня, в составе которого было создано пять комиссий. Туризм подробно рассматривался в деятельности двух комиссий - Комиссии по сотрудничеству в области культуры и в области образования ${ }^{1}$.

18 ноября 2015 г. между Беларусью и Китаем был подписан протокол к межправительственному соглашению о безвизовом туристическом режиме ${ }^{2}$. В настоящее время белорусы могут находиться в КНР без визы до 30 дней в течение одного визита, но не более 90 дней в году. У китайских туристов такие же условия нахождения в Беларуси. Безвизовый режим предусматривает туристические путешествия, бизнес-командировки, частные поездки, но учебная и профессиональная деятельность требуют получения специальной визы ${ }^{3}$.

Весной 2017 г. в рамках знакомства китайцев с Беларусью был организован пресс-тур представителей китайских СМИ. Как отметила сотрудница газеты «Вестник Цинхая» Сюэ Цзунь, число китайских туристов, которые посещают Беларусь, должно быть в разы больше (пока же доля китайских туристов во въездном потоке в Беларусь всего $0,4 \%)^{4}$. В рамках активизации межгосударственного сотрудничества в 2018 г. в Китае был проведён «Год туризма Беларуси в Китае»,

\footnotetext{
1 Belarus China - Комитет [Электронный pecypc]. URL: http://www.beIaruschina.by/ru/ committee-1586.html (дата обращения: 17.03.2021).

${ }^{2}$ Беларусь и Китай обсудили безвизовый туристический режим /FreeSMI.by [Электронный pecypc]. URL: https://freesmi.by/politika/214233 17.03.2021 (дата обращения : 17.03.2021).

3 Как Беларуси войти на туристический рынок Китая? [Электронный ресурс]. URL: https://rsti.by/o-nas/novosti/kak-belarusi-voyti-na-turisticheskiy-rynok-kitaya/ (дата обращения: 17.03.2021).

${ }^{4}$ Число китайских туристов в Беларуси должно быть в разы больше - журналист... [Электронный pecypc]. URL: https://www.belta.by/society/view/chislo-kitajskih-turistov-v-belarusidolzhno-byt-v-r... (дата обращения: 17.03.2021). Как по шелку: китайские тургруппы поедут в Беларусь без визы | Новости Белар... [Электронный ресурc]. URL: https://www.belta.by/ comments/view/kak-po-shelku-kitajskie-turgruppy-poedut-v-bel... (дата обращения: 17.03.2021).
} 
в ходе которого в Поднебесной в городах Чунцине и Шанхае были организованы туристические выставки.

Как же сделать Шелковый путь для туристов действительно «шелковым» и какую стратегию выстраивать здесь Беларуси?

Международная статистика свидетельствует, что каждый десятый турист в мире - китаец. На фоне выездного потока из КНР в 2019 г. в объеме 155 млн туристов число организованных китайских туристов в Беларусь составило 5121 человек, что выглядит каплей в море 5 . Только в 2020 г. китайские туристы потратили 215 млрд долл США, увеличив свои расходы в ходе путешествия по сравнению с 2014 годом в полтора раза 6 .

Что же интересует китайских туристов в Беларуси? Проведённый анализ свидетельствует, что средний возраст туристов из КНР 45-50 лет. Наибольший интерес у них вызывает история коммунизма, ностальгия по СССР, памятники В.И. Ленину, объекты Великой Отечественной войны (т.е. всё, что связано с так называемым в Китае «красным туризмом»), а также совместные белорусско-китайские предприятия - «БелДжи», индустриальный парк «Великий камень» куда вкладывается много инвестиций из Китая и куда можно возить группы китайских туристов, так как китайцы очень гордятся всем своим национальным ${ }^{7}$. Китайских туристов также интересуют в республике природные достопримечательности и шоптуры. Исходя из данных о покупках по системе tax-free, туристы из Китая увозят из республики ювелирные и меховые изделия, белорусскую обувь.

Для китайского туриста Беларусь во многом всё ещё ассоциируется с Россией. Поэтому, учитывая близость Беларуси и России, нам необходимо создавать совместные экскурсионные программы для китайских тургрупп. Например, Россия, организовав программу China Friendly (дружелюбно к китайцам) только в 2020 г., получила турист-

\footnotetext{
${ }^{5}$ В 2019 году китайские туристы совершили более шести миллиардов внутренних поездок [Электронный ресурс] Режим доступа: https://www.sb.by/articles/v-2019-godu-kitayskie-turistysovershili-bolee-6-milliardo... (Дата доступа: 17.03.2021); Итоги по въезду-выезду туристов в 2019 году: Египет снова направление №1‥ [Электронный ресурс] Режим доступа: https://www.toursoyuz.by/2020/03/12/itogi-po-vezdu-vyezdu-turistov-v-2019-godu-e. (Дата доступа: 06.04.2021).

${ }^{6}$ Как по шелку: китайские тургруппы поедут в Беларусь без визы. Новости Беларуси [Электронный ресурc]. URL: https://www.belta.by/comments/view/kak-po-shelku-kitajskie-turgruppypoedut-v-bel... (Дата обращения: 17.03.2021).

Как по шелку: китайские тургруппы поедут в Беларусь без визы. Новости Белар... [Электронный pecypc]. URL: https://www.belta.by/comments/view/kak-po-shelkukitajskie-turgruppy-poedut-v-bel... (Дата обращения: 17.03.2021).
} 
ский поток из КНР в объёме почти 700 тыс. человек ${ }^{8}$. Как мы видим, сугубо «чистых» туристов, желающих посетить Беларусь, немного, а использовать географическое положение соседних стран - это крайне важно. Учитывая же, что между Беларусью и Россией в июне 2020 г. подписано межправительственное соглашение о взаимном признании виз иностранных граждан на территории стран Союзного государства, кооперация в туристском плане с Москвой способна дать положительные результаты 9 .

Анализ выездного турпотока КНР свидетельствует о том, что 75\% китайских граждан путешествуют, как правило, самостоятельно. Беларусь же пытается сделать приоритетным организованный туризм. Как показывает первичный опыт, этот вариант более сложный, но возможный. Например, Республиканское унитарное предприятие «Центркурорт» совместно с белорусским ООО «Культурно-деловым центром «Ювизит» и китайской компанией National Travel Service Group Corporation Limited организовали тур для 2,5 тыс. сотрудников китайской компании Perfect в Беларусь в мае 2019 г. Это был бизнестур, так как гости посетили промышленные предприятия Минска, объекты историко-культурного наследия Беларуси (историкокультурный комплекс «Линия Сталина», Музейный комплекс старинных народных ремёсел и технологий «Дудутки», Мирский и Несвижский замки), познакомились с белорусской национальной кухней $^{10}$. Как отметил начальник филиала «Белинтурист» РУП «Центркурорт» Алексей Стрельченко «считать, что к нам массово поедут индивидуальные туристы, не стоит, а на группы мы рассчитывать можем» ${ }^{11}$. В настоящее время предприятием разработаны туры по Беларуси для китайских туристов, в том числе комбинированные с посещением России и стран Евросоюза. В Пекине и Шанхае проведена презентация белорусского туристического продукта, подписано со-

\footnotetext{
8 Как по шелку: китайские тургруппы поедут в Беларусь без визы. Новости Белар... [Электронный pecypc]. URL: https://www.belta.by/comments/view/kak-po-shelkukitajskie-turgruppy-poedut-v-bel... (дата обращения: 17.03.2021).

9 Китай заинтересован в организации турмаршрутов в Беларусь с включением сос... [Электронный ресурc]. URL : https://www.belta.by/economics/view/kitaj-zainteresovan-vorganizatsii-turmarshruto... (дата обращения : 17.03.2021).

10 Более 2,5 тыс. туристов из Китая посетили Беларусь во время бизнес-тура [Электронный pecypc]. URL: https://www.belta.by/society/view/bolee-25-tys-turistov-iz-kitaja-posetili-belarusvo-v...(дата обращения : 17.03.2021).

11 Как по шелку: китайские тургруппы поедут в Беларусь без визы | Новости Белар... [Электронный pecypc]. URL: https://www.belta.by/comments/view/kak-po-shelkukitajskie-turgruppy-poedut-v-bel... (дата обращения : 17.03.2021).
} 
глашение о сотрудничестве с Центральной международной туристической компанией Всекитайской федерации профсоюзов. В Пекине открывается Белорусский туристический информационный центр ${ }^{12}$.

Ещё одно перспективное направление, которое может привлечь китайских путешественников - это активизация рынка медицинского туризма. Понимая, что китайский рынок не похож ни на какие другие - быстрого результата здесь быть не может. Однако учитывая популярность в Китае «сарафанного радио» и принимая во внимание, что в Беларуси сегодня увеличивается число китайских студентов, строителей, работников китайских предприятий в технопарке «Великий камень», представителей делегаций, бизнес-сообщества - услуги медицинского туризма могут заинтересовать гостей. Проведённый анализ свидетельствует, что только в 2016 г. 500 тыс. китайцев отправились за границу на лечение, а средняя стоимость путёвки составила 7,5 тыс. долл США. Среди топ - 5 стран, которые пользуются наибольшим спросом у китайцев в сфере медицинского туризма - Япония, Южная Корея, США, Тайвань, Германия. Наиболее востребованными направлениями лечения являются онкологические заболевания, кардиологическое обследование, лечение гепатита С, физиотерапия, омоложение, т.е. те направления, которые успешно развиваются и в Беларуси ${ }^{13}$. В настоящее время спрос на услуги медицинского туризма в Республике Беларусь среди иностранных граждан растёт. В 2017 г. республику с медицинскими целями, включающими получение медицинской помощи в больничных учреждениях и оздоровления в санаториях, посетило 190 тыс. человек из 128 стран мира ${ }^{14}$.

По некоторым видам медицинских услуг (ЭКО, маммопластика, эндопротезирование) цены в 2-2,5 раза ниже, чем в европейских странах и странах ближнего зарубежья. В белорусских центрах косметологической и пластической хирургии до 50\% обращающихся пациентов составляют граждане России, стран Балтии, Германии, США [1]. Привлекающим фактором для иностранных пациентов в белорусские клиники является высокое качество медицинских услуг, которое

\footnotetext{
12 «Центркурорт» выходит на рынок туристических услуг Китая [Электронный ресурс]. URL: https://www.belta.by/society/view/tsentrkurort-vyhodit-na-rynok-turisticheskih-uslug-...(дата обращения: 17.03.2021).

${ }^{13}$ Справка о системе здравоохранения и медицинского страхования в КНР // Текущий архив Министерства здравоохранения Республики Беларусь, 2020 г. 4 с.

${ }^{14}$ Медицинский туризм в Беларуси: лечение, сервис, цены // Туристический путеводитель «Лучшее в Беларуси»] [Электронный pecypc]. URL : https://bestbelarus.by/info/blog/ meditsinskiy-turizm-v-belarusi-lechenie-servis-tseny (дата обращения : 01.12.2020).
} 
обеспечивается высокой квалификацией белорусских врачей и хорошей технической оснащённостью клиник. Как отмечает директор ООО «Ви энд Ви Медикал» В. Андросов, «необходимо создание специализированных центров по таким направлениям, как офтальмология, стоматология, эстетическая медицина. Медицинские учреждения республики показывают зарубежным гостям высокий уровень оказания услуг, но такие центры должны хорошо ориентироваться на рынке медицинского туризма, оперативно решать любые логистические вопросы, демонстрировать высокий уровень сервиса» ${ }^{15}$.

Вместе с тем, в работе с китайскими туристами имеется и ряд трудностей, которые не позволяют стремительно нарастить въездной поток в республику. Во-первых, в стране специальной туристской инфраструктуры для китайских туристов фактически нет. Это касается в первую очередь китайской кухни, когда на маршруте необходимо организовать приём пищи непременно с блюдами китайской кухни. Трудно организовать такое питание в г. Минске, не говоря о регионах страны, которыми уже заинтересовались гости из Поднебесной ${ }^{16}$. Вовторых, в туристических поездках гости из КНР привыкли рассчитываться картами платёжной системы UnionPay, а в Беларуси это сделать пока сложно. В-третьих, помимо необходимости увеличения количества путеводителей и карт на китайском языке, необходимо обеспечить подготовку гидов - переводчиков. Национальное агентство по туризму при Министерстве спорта и туризма Республики Беларусь готовит первую такую группу в количестве 13 человек, а пока же китайские туроператоры преимущественно работают с китайцами - выпускниками наших вузов, нашедшими работу в технопарке «Великий камень» и не имеющими права работать в сфере туризма. Вчетвёртых, с организованными китайскими группами должны работать только местные туроператоры (такой список уполномоченных агентств с обеих сторон должен быть определён Министерством спорта и туризма Республики Беларусь) или совместные турпредприятия. В противном случае (как свидетельствует опыт России) китайцы попытаются создать свою инфраструктуру, используя диаспору в республике в части организации питания, экскурсионного обслужи-

\footnotetext{
${ }^{15}$ Справка о системе здравоохранения и медицинского страхования в КНР // Текущий архив Министерства здравоохранения Республики Беларусь, 2020 г. 4 с.

16 Как Беларуси войти на туристический рынок Китая? [Электронный ресурc]. URL: https://rsti.by/o-nas/novosti/kak-belarusi-voyti-na-turisticheskiy-rynok-kitaya/ (дата обращения: 17.03.2021).
} 
вания, замкнув на ней финансовый цикл ${ }^{17}$. В-пятых, в Китае действуют очень жёсткие договорные условия и финансовые правила. О предоплатах вообще и речи быть не может, оплата только по факту в течение 90 дней после оказания услуг. Более того, зачастую с китайской стороны можно столкнуться с выплатой так называемого «депозита качества», когда качество услуги, по мнению клиента, не соответствует цене и китайский партнёр удерживает часть оплаты. Такие рекламации трактуются китайской стороной по-своему и документально никак не подтверждаются ${ }^{18}$.

Заключение. Принимая во внимание проблемы в организации туристского обмена с Поднебесной, Беларуси, на наш взгляд, необходимо тщательно координировать свою туристическую политику в отношении КНР не только с Российской Федерацией, но и со странами, входящими в ЕврАзЭС, вырабатывая общие правила сотрудничества с китайской стороной, дабы проект «шёлкового пути» был действительно «шёлковым» и для туристического бизнеса наших государств.

Положительным аспектом в этом плане является подключение Беларуси к евразийскому приложению «Путешествую без COVID19», однако пока это лишь маленький эпизод, свидетельствующий о необходимости большой совместной системной работы, которую предстоит государством осуществить ${ }^{19}$.

Как отметил известный российский исследователь С. Глазьев «необходима конкретизация целеполагания и подкрепление прагматических устремлений государств-членов серьезной научно-исследовательской и практической работой по актуализации совместного культурно-исторического и духовного наследия народов Евразии» ${ }^{20}$.

\section{Библиографические ссылки}

1. Милашевич Е. А. Система организации экспорта медицинских услуг Беларуси: проблемы и перспективы развития // Региональное развитие: проблемы и перспективы: матер. VI Bсерос. научн.-практ. заочн. конфер. с междунар. участием, Нефтекамск, 17 мар. 2017 г. Нефтекамск: НФ БашГУ, 2017. С. 30-36.

17 Как Беларуси войти на туристический рынок Китая? [Электронный ресурс]. URL: https://rsti.by/o-nas/novosti/kak-belarusi-voyti-na-turisticheskiy-rynok-kitaya/ (дата обращения: 17.03.2021).

18 Там же.

${ }^{19}$ Беларусь присоединилась к евразийскому приложению «Путешествую без COVI...» [Электронный pecypc]. URL: https://news.mail.ru/politics/45840541/ (дата обращения: 06.04.2021).

${ }^{20}$ Сергей Глазьев: «Большое евразийское партнерство создаст осн...» [Электронный ресурс]. URL: https://zvezdaweekly.ru/news/t/2019313107-2Yqsz... (дата обращения: 14.03.2019). 
2. Гайдукевич Л.М., Пильгун Е.В. Место и роль Китая в формировании многополярного мира // Труды ФМО: сб.науч.тр. Минск: БГУ, 2016. Вып. VII. С. 20-23.

3. Гэ Инь, Гайдукевич Л.М. Деятельность КНР по развитию международного туризма на современном этапе // Актуальные проблемы международных отношений и глобального развития. Минск, 2015. Вып. 3: С. 25-38.

4. Криштапович Л.Е., Мацель В.М. Китайская Народная Республика на пути в XXI век: монография. Минск: Академия управления при Президенте РБ, 2004. 131 с.

5. Рудый К.В. Инновационное развитие с китайской спецификой // Финансы, учет, аудит. 2008. № 10. С. 22-25.

6. Мясников В. Беларусь и Китай: перспективы и партнерство в АТР в 21 веке // Проблемы Дальнего Востока. 2008 г. № 6. С. 35-37.

7. Чебанова Э.Ю. Принципы многовекторности во внешней политике Республики Беларусь на примере белорусско-китайского сотрудничества // Международный научно-исследовательский журнал. 2015. № 1(32). С. 67-69.

8. Бао Ин. Китайско-российское сотрудничество в области образования, науки, техники и молодежных обменов (2003-2018) / Автореферат диссертации на соискание ученой степени кандидата исторических наук по специальности 07.00.15 - история международных отношений и внешней политики. Минск. 2020. 22 с.

Дата поступления статьи: 26.05.2021.

Автор: Гайдукевич Леонид Михайлович - доктор исторических наук, профессор кафедры международного туризма Белорусского государственного университета; e-mail: lgaidukevich@mail.ru

\title{
COOPERATION BETWEEN BELARUS AND CHINA IN THE SPHERE OF TOURISM: CURRENT STATE AND DEVELOPMENT PROSPECTS
}

\author{
L. M. GAJDUKEVICH \\ Belarusian State University, Minsk, Republic of Belarus
}

\begin{abstract}
The article deals with the problems of forming a unified tourism policy within the framework of the Eurasian Economic Union in relation to the People's Republic of China (PRC). Using the example of cooperation between the Republic of Belarus and the PRC, the specifics and tools used for interaction between the two countries from 2014 to 2020 are revealed. Both States attach particular importance to cooperation in the humanitarian field, where tourism is an effective tool of modern communication policy. The author draws attention to the experience of the China, which was the first to withstand the impact of the COVID-19 coronavirus and currently shows a sample of a fairly effective recovery, including the tourism business. The main trends of the modern international tourism market are analyzed, the gradual intensification of international cooperation between Belarus and PRC in the tourism sector is shown, the specifics of the visa-free policy of Belarus with China are revealed, the features of bilateral relations in the organization of tourist exchange with the China are described, the main directions, problems and prospects of tourism development are identified. Special attention is paid to a promising direction that can
\end{abstract}


attract Chinese travelers - medical tourism. The author also described in detail the difficulties that Belarusian travel companies face when working with tourists from China, which do not allow increasing the flow of entry into the republic and gives recommendations for solving these problems.

Key words: tourism; tourist services; Belarusian-Chinese cooperation; visa-free policy; pandemic; COVID-19.

For citations: Gajdukevich L. M. (2021). Belorussko-kitajskoe sotrudnichestvo v sfere turizma: sostoyanie i perspektivy razvitiya [Cooperation between Belarus and China in the sphere of tourism: current state and development prospects]. in: Actual problems of international relations and global development: collection of scientific papers. Minsk, Vol. 9, p. 27-36. https://doi.org/10.33581/2311-9470-2021-9-27-36

\section{References}

1. Milashevich E. A. (2017). Sistema organizacii jeksporta medicinskih uslug Belarusi: problemy i perspektivy razvitija [The system of organizing the export of medical services in Belarus: problems and development prospects]. In: Regional development: problems and prospects: mater. VI All-Russia scientific and practical confer. with int. participation. Neftekamsk: NF BashGU. P. 3036. (In Russ.).

2. Gajdukevich L. M., Pil'gun E.V. (2016). Mesto i rol Kitaya v formirovanii mnogopolyarnogo mira [The place and role of China in the formation of a multipolar world]. In: Working Papers of The Faculty Of International Relations. Minsk. Vol. VII. P. 20-23. (In Russ.).

3. In Ge', Gajdukevich L.M. (2015) Deyatel'nost` KNR po razvitiyu mezhdunarodnogo turizma na sovremennom e'tape [Activities of China development of international tourism at the present stage]. In: Actual problems of international relations and global development: collection of scientific papers. Minsk. Vol. 3. P. 25-38. (In Russ.).

4. Krishtapovich L.E., Macel' V.M. (2004) Kitajskaya Narodnaya Respublika na puti v XXI vek: monografiya [The People's Republic of China on the way to the XXI century: monograph]. Minsk: Academy of Management under the President of the Republic of Belarus. 131 p. (In Russ.).

5. Rudyj K.V. (2008). Innovacionnoe razvitie s kitajskoj specifikoj [Innovative development with Chinese specifics]. In: Finance, accounting, audit. No. 10. P. 22-25. (In Russ.).

6. Myasnikov V. (2008). Belarus' i Kitaj: perspektivy i partnerstvo v ATR v 21 [Belarus and China: prospects and partnership of the Asia-Pacific region in the 21st century]. In: Problems of the Far East. No. 6. P. 35-37. (In Russ.).

7. Chebanova E'.Yu. (2015). Principy mnogovektornosti vo vneshnej politike Respubliki Belarus' na primere belorussko-kitajskogo sotrudnichestva [Principles of multi-vector approach in the foreign policy of the Republic of Belarus on the example of Belarusian-Chinese cooperation]. In: International Research Journal. No. 1(32). Chast` 4. P. 67-69. (In Russ.).

8. In Bao (2020). Kitajsko-rossijskoe sotrudnichestvo v oblasti obrazovaniya, nauki, tekhniki i molodezhnyh obmenov (2003-2018) [Cooperation between Russia and China in the field of education, science, technology and youth exchanges (2003-2018)]. Abstract of the dissertation for the degree of Candidate of Historical Sciences in the specialty 07.00.15 - History of international relations and foreign policy. Minsk. 22 p. (In Russ.).

Received: 26.05 .2021 .

About authors: Gajdukevich L. M. - Doctor of Sciences in History, Professor of the Department of International Tourism of the Belarusian State University; e-mail: Igaidukevich@mail.ru. 